
\title{
.
}

\section{ALIMENTOS COM E SEM GLÚTEN - ANÁLISE COMPARATIVA DE PREÇOS DE MERCADO}

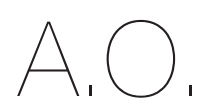

ARTIGO ORIGINAL

${ }^{1}$ Associação Portuguesa de Celíacos,

Avenida Júlio Dinis N. ${ }^{\circ 23}$, $S / L \mid$

1050-130 Lisboa, Portugal

${ }^{2}$ Escola Superior de Tecnologia da Saúde de Lisboa,

Av. D. João II, Lote 4.69.01 1990-096 Lisboa, Portugal

*Endereço para correspondência: Daniela Afonso

Associação Portuguesa de Celíacos

Celiacos

Avenida Jullio Dinis

1050-130 Lisboa
daniela.afonso@celiacos.org.pt

Histórico do artigo:

Recebido a 21 de janeiro de 2016 Aceite a 29 de março de 2016

\author{
GLUTEN AND GLUTEN-FREE PRODUCTS - PRICE \\ DIFFERENCE
}

Daniela Afonso', ; Rita Jorge'; Ana Catarina Moreira²

\section{RESUMO}

A doença celíaca é uma doença autoimune que se traduz numa sensibilidade alimentar crónica ao glúten, que ocorre em indivíduos geneticamente suscetíveis. Em consequência da ingestão de glúten o organismo desenvolve uma reação imunológica contra o próprio intestino. A dieta isenta de glúten é o único tratamento conhecido para esta patologia, adotada para toda a vida, deve ser rigorosa, completa, equilibrada e variada.

O presente estudo pretende comparar preços entre categorias de produtos alimentares sem glúten e produtos equiparáveis com glúten. É também objetivo do estudo avaliar o impacto desta despesa no rendimento familiar associado ao cumprimento de uma dieta sem glúten e comparar os resultados da presente recolha de dados com um estudo anterior.

O preço por quilograma dos produtos específicos sem glúten e dos produtos com glúten foi recolhido através de consulta online. Analisou-se o preço por tipo de produto incluído nas 7 categorias alimentares (pão, massas, farinha, cereais de pequeno-almoço, bolachas/bolos, barras de cereais e alimentação preparada), de todos os produtos específicos sem glúten, e procedeu-se à recolha de preços de um igual número de produtos equiparáveis com glúten. Atualizou-se o preço dos alimentos incluídos num cabaz alimentar essencial com glúten, desenvolvido pela Associação Portuguesa dos Nutricionistas.

Em todas as categorias de produtos analisadas foram mais caros os Produtos Alimentares Específicos sem Glúten. As maiores diferenças de preço dos produtos específicos sem glúten em relação aos com glúten são observadas na categoria das massas, pão e bolachas. O preço do cabaz alimentar essencial sem glúten representa um aumento de $26 \%$ em relação ao equivalente com glúten. O custo acrescido para uma família seguir a Dieta Isenta de Glúten para um mês é de $110 €$, e semanal por indivíduo de 8,6 €. O presente estudo demonstra que, em todas as categorias, os Produtos Alimentares Específicos sem Glúten estudados são mais dispendiosos que os produtos alimentares equiparáveis com glúten. O custo do cabaz alimentar essencial sem glúten é superior em relação ao equivalente com glúten, representando mais de metade do orçamento das famílias com 2 adultos, que auferem o ordenado mínimo nacional. Em comparação com um estudo realizado anteriormente a diferença entre preços de Produtos Alimentares Específicos sem Glúten e com glúten diminuiu na maioria das categorias.

\section{PALAVRAS-CHAVE}

Dieta Isenta de Glúten, Doença Celíaca, Preços, Produtos com Glúten, Produtos Específicos sem Glúten

ABSTRACT

Celiac disease is an autoimmune chronic disease characterized by gluten sensitivity, which manifests in genetically susceptible individuals. When people with celiac disease consume gluten, their body mounts an immune response that attacks the small intestine. Being so, the only known treatment for celiac disease is a lifelong strict gluten-free diet that should be complete, balanced and varied. The objetives of these study were compare prices between categories of gluten-free products and equivalents with gluten, assess costs in a family income of a gluten-free diet and compare the results with a previous study.

The price per kilogram of gluten and gluten-free products was collected through online search. Prices were analyzed by product type, among seven categories (bread, pasta, flour, breakfast cereals, cookies/ cakes, cereal bars and ready meals) of all gluten-free products, and the same prices of equivalents gluten products were collected. The food prices included in the essential food basket with gluten, developed by Portuguese nutritionists association, were posteriorly adjusted to the gluten-free diet.

In all categories of products analyzed gluten-free products were more expensive. Largest differences were observed in food categories such as pasta, bread and cookies categories. It was found a difference of $26 \%$ in prices when comparing gluten-free essential food basket and the gluten equivalent. The added cost for a family to follow a gluten-free diet for one month is $110 €$ and weekly per person is $8,6 €$.

The present study demonstrates that, in all categories, gluten-free products studied are more expensive than equivalents gluten products. The price of the gluten-free essential food basket is greater than the equivalent with gluten, it represents more than a half of a family budget, of national minimum salary. Compared to a previous study the difference between prices of gluten-free and gluten products decreased in most categories.

KEYWORDS

Gluten-free diet, Celiac Disease, Price, Gluten-free products, Gluten products 


\section{INTRODUÇÃO}

A Doença Celíaca (DC) é uma doença autoimune que se traduz numa sensibilidade alimentar crónica ao glúten, e que ocorre em indivíduos geneticamente suscetíveis. A ingestão de glúten leva o organismo a desenvolver uma reação imunológica contra o próprio intestino, provocando lesões ao nível da mucosa e interferindo com a absorção dos nutrientes (1).

Em Portugal a DC encontra-se subdiagnosticada, com uma prevalência de 1:134, taxa próxima da encontrada noutras populações europeias (2).

O único tratamento conhecido para a DC consiste numa Dieta Isenta de Glúten (DIG) para toda a vida, sendo o glúten, uma fração proteica do trigo, centeio, cevada, aveia ou suas variedades cruzadas e derivados $(3,4)$. A alimentação do indivíduo com doença celíaca deve ser rigorosa, completa, equilibrada e variada, seguindo os princípios de uma alimentação saudável, devendo os alimentos com glúten serem substituídos por outros cujas matérias-primas sejam isentas de glúten (5).

Os "géneros alimentícios destinados a pessoas com intolerância ao glúten" são géneros alimentícios destinados a uma alimentação específica que são especialmente produzidos, preparados, e/ou transformados para responder às necessidades dietéticas especiais de pessoas com intolerância ao glúten. A rotulagem, a apresentação e a publicidade desta tipologia de produtos alegam a menção "isento de glúten”. A menção «isento de glúten» só pode ser utilizada se os géneros alimentícios, tal como vendidos ao consumidor final, não contiverem mais de $20 \mathrm{mg} / \mathrm{kg}$ de glúten (6).

Na DIG são considerados vários tipos de produtos alimentares sem glúten: os naturalmente isentos (fruta, hortícolas, leite, leguminosas, etc.); os produtos alimentares processados desde que não contenham ingredientes com glúten na sua composição (gelados, enchidos, molhos industriais, etc.); e os Produtos Alimentares Específicos sem Glúten (PAESG) (massa, pão, cereais, bolachas, entre outros.). O preço dos PAESG tende a ser mais elevado comparativamente aos alimentos convencionais comuns, não só como resultado da necessidade de utilização de grãos alternativos aos cereais proibidos e ingredientes adicionais, como a todas as medidas de segurança alimentar para evitar contaminações cruzadas com glúten (na produção/ transformação/ embalamento) necessitando a indústria, entre outras medidas, de ter linhas dedicadas ou mesmo instalações exclusivas, mas também porque o processo de desenvolvimento destes produtos carece de forte componente de investigação, para que as suas características organoléticas e nutricionais vão ao encontro das preferências e necessidades nutricionais dos indivíduos com doença celíaca $(6,7)$.

O preço dos PAESG é uma das razões apontadas para o não cumprimento da DIG. Num estudo realizado em 2008 , 85\% dos inquiridos referiu o facto dos alimentos sem glúten apresentarem um custo elevado, traduzindo-se em dificuldades sentidas no cumprimento da DIG (8). Para reforçar esta relação, numa amostra de 201 doentes celíacos portugueses, 96 referiram consumir alimentos com glúten. Destes, 21,9\% apontam o preço dos PAESG como a razão principal para o não cumprimento da dieta. Adicionalmente, 95\% da amostra mostrou-se insatisfeita relativamente ao custo do PAESG experimentados (9). Num estudo realizado em crianças e adolescentes, o custo dos alimentos sem glúten foi indicado como um dos fatores interferentes no cumprimento da DIG (10).

A influência da não adesão ao tratamento com a DIG aliada ao número substancial de doentes não diagnosticados, estão na base do desenvolvimento de malignidades e da forma refratária da DC (11).
As complicações neoplásicas incluem linfomas não-Hodgkin das células T e B, que podem ser intestinais ou extraintestinais, adenocarcinomas orofaríngeo e esofágico, cancro do intestino delgado e grosso, do sistema hepatobiliar e pâncreas $(12,13)$. A adesão estrita à DIG parece ser a única possibilidade de prevenir o aparecimento de cancro (12).

Os PAESG são empiricamente mais dispendiosos que os equivalentes com glúten (CG) apesar da crescente variedade de marcas e produtos lançados no mercado nos últimos anos. O custo acrescido associado ao cumprimento da DIG e a diferença em relação à alimentação tradicional com glúten é desconhecida em Portugal.

\section{OBJETIVO}

O presente estudo pretende comparar preços entre categorias de produtos alimentares sem glúten e produtos equiparáveis com glúten. É também objetivo do estudo avaliar o impacto desta despesa no rendimento familiar associado ao cumprimento de uma dieta sem glúten e comparar os resultados da presente recolha de dados com um estudo anterior.

\section{METODOLOGIA}

A recolha de dados dos preços dos produtos alimentares foi realizada entre julho e setembro de 2013.

Definição das categorias - Foram considerados os seguintes tipos de alimentos, integrados nas principais categorias que necessitam de substitutos sem glúten: pão (baguetes, pão de cereais, pão de forma e tostas), massa (massa esparguete, massa espiral e massa macarrão), farinha (farinha para bolos e farinha para panificação), cereais de pequeno-almoço (cereais tipo corn flakes, cereais infantis de chocolate e cereais infantis de mel), barras de cereais, bolachas/ bolos (bolachas wafers, bolachas de/ com chocolate, bolachas crackers/ água e sal, bolacha maria, bolachas recheadas/ doce de fruta, bolos recheados e bolos simples) e alimentação preparada (base de pizza, panados de peixe, lasanha e pizza congelada) (14-17). A lista inclui alimentos essenciais como pão, massas, farinha, cereais de pequeno-almoço, bolachas maria e crackers, mas também alimentos de conveniência, não essenciais, como a alimentação preparada, bolos e bolachas recheadas, que integram as despesas das famílias em produtos alimentares (18).

Recolha de preços - O preço dos PAESG e dos produtos com glúten foi recolhido através de consulta online, por conveniência e uniformização de dados relativos à variação de preços por regiões do país. A consulta de preços realizou-se no portal de 8 lojas que disponibilizam este serviço, duas de cada tipo de loja [supermercados (grande distribuição), lojas online, lojas especializadas e lojas de qualidade (lojas que vendem produtos gourmet ou dietéticos especiais, e oferecem uma ampla variedade de produtos selecionados, muitas vezes importados)]. Analisou-se o preço por tipo de produto, de todos os PAESG encontrados nas 8 lojas, incluindo produtos de marcas de fabricante e marcas próprias. Considerando o número de PAESG encontrados, procedeu-se à recolha de preços de um igual número de produtos equiparáveis com glúten, por tipo de alimento, nos 2 supermercados. Os produtos equiparáveis foram considerados por características físicas semelhantes (apresentação, formato), equiparação em sabor e textura e inclusão no mesmo tipo de alimento (ex. baguetes, massa espiral, base de pizza, etc.). O critério definido na recolha dos produtos com glúten, teve como base a seleção de 50\% dos produtos identificados com a relação PVP/kg, mais elevada e mais reduzida. Para efeitos comparativos os preços foram recolhidos em euros por quilograma de produto $(€ / \mathrm{kg})$. 
Análise por tipo de loja - De forma a incluir produtos com glúten de lojas especializadas e de qualidade para efeitos de comparação, procedeu-se à recolha do preço do produto mais barato, mais caro e intermédio por tipo de produto e por loja. Os dados recolhidos dos produtos com glúten das lojas especializadas e de qualidade foram utilizados exclusivamente para a análise comparativa complementar da diferença de preços dos PAESG e com glúten por tipo de loja.

As lojas online estudadas comercializam exclusivamente produtos sem glúten.

Cabaz alimentar essencial - Para analisar o custo associado ao cumprimento da DIG, foi utilizado um estudo da Associação Portuguesa dos Nutricionistas (APN) que criou, em janeiro de 2011, um cabaz alimentar essencial, tendo em consideração as necessidades nutricionais estabelecidas pela Roda dos Alimentos, como proposta de base para uma alimentação adequada de uma família padrão portuguesa (um homem, uma mulher e um adolescente rapaz) (19). Para a atualização dos preços foi aplicada a taxa de variação média anual verificada em 2011, 2012 e setembro de 2013, do índice de preços no consumidor (IPC) da classe de produtos alimentares e bebidas não alcoólicas, divulgada pelo Instituto Nacional de Estatística (INE) $(20,21)$.

Os grupos de alimentos que necessitam de substituição por PAESG são os do pão, cereais, bolachas e massas. O acréscimo de custo dos PAESG foi calculado através dos resultados da percentagem de diferença de preço dos PAESG em relação aos produtos com glúten. Considerando a definição do cabaz original (alimentos da Roda dos Alimentos), foram considerando no cabaz sem glúten os seguintes tipos de produtos: pão de cereais, cereais Corn Flakes, média das bolachas Crackers/ Água e sal e bolachas Maria, e a categoria das massas.

Foi efetuada uma análise comparativa da despesa dos produtos presentes no cabaz alimentar essencial, com e sem glúten, no rendimento mensal familiar, utilizando-se para isso, duas fontes de informação: o rendimento médio líquido mensal por tipologia de agregado familiar estabelecido pelo INE (22), ou seja, $2546 €$ para um agregado familiar composto por dois adultos e um jovem, e o cálculo do rendimento mensal auferido por dois adultos com o ordenado mínimo nacional, ou seja, $485 €(23)$.

\section{RESULTADOS}

Foram analisados 742 produtos alimentares de 129 marcas, e de 7 categorias, provenientes de 8 lojas integradas no estudo. Considerando que um mesmo produto pode estar presente em mais que uma loja, foram totalizados 970 dados relativos ao preço.

Nas 7 categorias de produtos alimentares analisadas, os PAESG evidenciaram preços mais elevados em todos os casos analisados, conforme se pode visualizar no Gráfico 1.

Percentualmente, as maiores diferenças de preço dos PAESG em relação àqueles com glúten, Gráfico 1, são observadas na categoria das massas (com preços 4 vezes superiores), pão (com preços 3 vezes mais elevados) e bolachas, com diferenças de preços que variam entre $300 \%$ e $65 \%$.

Dos 23 tipos de produtos analisados, expressos na Tabela 1, as barras de cereais apresentam a maior diferença de preço por quilograma $(20,5 €)$ e os panados de peixe a menor $(2,2 €)$, correspondendo estes à menor diferença percentual e a massa esparguete ao valor mais elevado (381\%).

Verifica-se, nos PAESG um aumento de preço de 35\% da marca de fabricante em relação à marca própria, Gráfico 2, nos produtos com glúten o aumento é de $126 \%$.

Os supermercados são o tipo de loja que apresenta valores menores no preço dos PAESG, a diferença entre os restantes é pouco significativa $(0,60 € / \mathrm{kg})$. É também, nos supermercados que se verifica uma maior diferença (107\%) entre o preço dos produtos com glúten e dos PAESG (Gráfico 3).

O preço do cabaz alimentar essencial sem glúten (Tabela 2), representa um aumento de $26 \%$ em relação ao equivalente com glúten. O custo acrescido para uma família seguir a DIG para um mês é de $110 €$, e semanal por indivíduo de 8,6 €.

O custo com a DIG representa $21 \%$ do rendimento médio líquido para o agregado familiar considerado. Quando comparado com o orçamento de uma família, com um rendimento equivalente a duas retribuições mínimas nacionais, verificamos, que representa 55\%.

A comparação dos resultados da presente recolha de dados com um estudo realizado em 2006 (24), apresentados na Tabela 3, evidencia que a diferença entre preços de PAESG e com glúten diminuiu na maioria das categorias, com exceção das categorias: alimentação

\section{Gráfico 1}

Preços médios por categorias de produtos alimentares e percentagem de diferença de preço

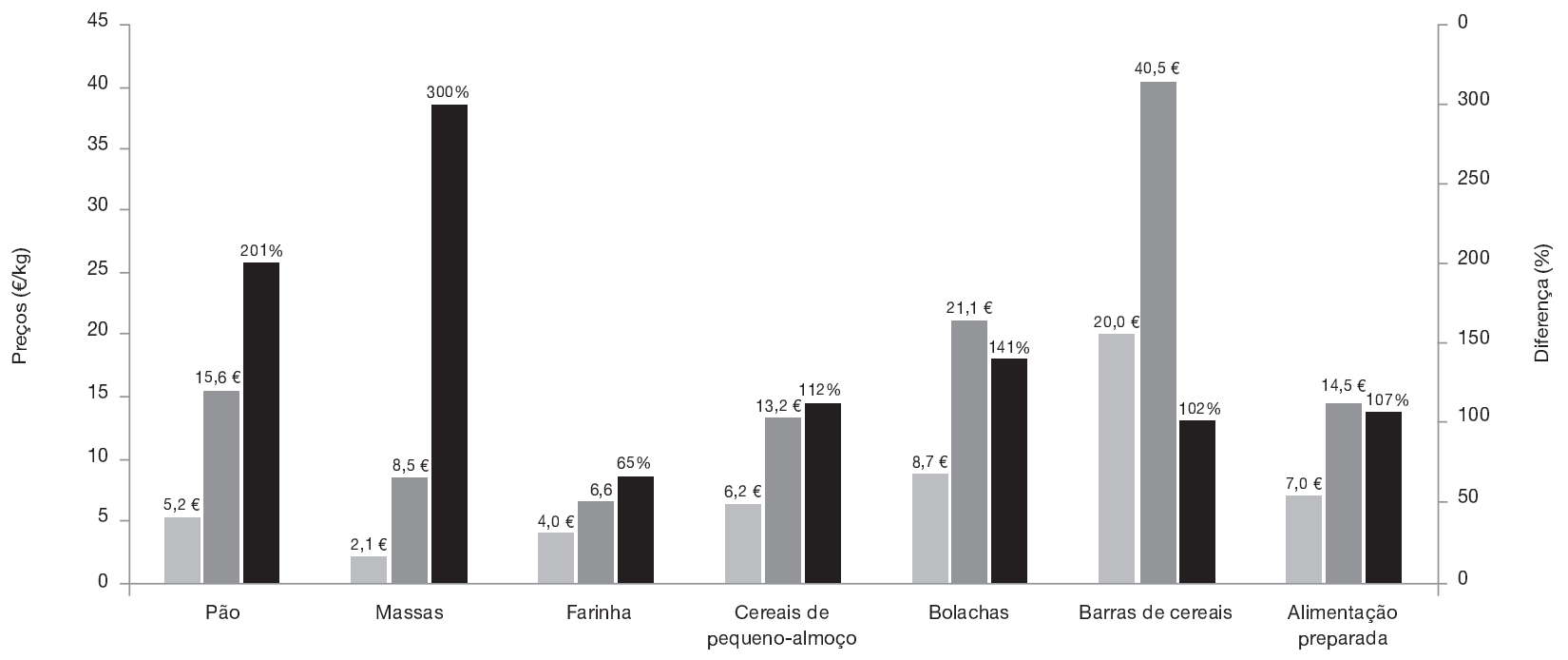


Preços médios por tipos de produtos

\begin{tabular}{|c|c|c|c|c|c|}
\hline \multirow[b]{2}{*}{ CATEGORIA } & \multirow[b]{2}{*}{ TIPOS DE PRODUTOS } & \multicolumn{2}{|c|}{ MÉDIA DE PREÇOS (€) } & \multirow[b]{2}{*}{ DIFERENÇA ( $€$ ) } & \multirow[b]{2}{*}{ DIFERENÇA (\%) } \\
\hline & & COM GLÚTEN & SEM GLÚTEN & & \\
\hline \multirow{4}{*}{ Pão } & Baguetes & 3,29 & 14,72 & 11,43 & 347 \\
\hline & Pão de cereais & 3,62 & 14,87 & 11,25 & 311 \\
\hline & Pão de forma & 4,72 & 12,12 & 7,4 & 157 \\
\hline & Tostas & 8,48 & 21,86 & 13,38 & 158 \\
\hline \multirow{3}{*}{ Massas } & Esparguete & 1,66 & 7,99 & 6,33 & 381 \\
\hline & Espirais & 2,78 & 8,86 & 6,08 & 219 \\
\hline & Macarrão & 1,99 & 8,66 & 6,67 & 335 \\
\hline \multirow{2}{*}{ Farinha } & Farinha para bolos & 5,67 & 8,06 & 2,39 & 42 \\
\hline & Farinha para panificação & 2,19 & 5,31 & 3,12 & 142 \\
\hline \multirow{3}{*}{ Cereais de pequeno-almoço } & Cereais Corn Flakes & 4,87 & 11,92 & 7,05 & 145 \\
\hline & Cereais infantis de chocolate & 7,18 & 13,98 & 6,8 & 95 \\
\hline & Cereais infantis de mel & 5,51 & 12,79 & 7,28 & 132 \\
\hline \multirow{7}{*}{ Bolachas/ Bolos } & Bolacha wafers & 10,66 & 25,57 & 14,91 & 140 \\
\hline & Bolacha crackers/ água e sal & 6,23 & 20,16 & 13,93 & 224 \\
\hline & Bolachas de/ com chocolate & 9,68 & 22,2 & 12,52 & 129 \\
\hline & Bolacha Maria & 4,54 & 10,29 & 5,75 & 127 \\
\hline & Bolachas recheadas/ doce de fruta & 9,47 & 18,7 & 9,23 & 97 \\
\hline & Bolos recheados & 8,96 & 19,25 & 10,29 & 115 \\
\hline & Bolos simples & 6,75 & 22,75 & 16 & 237 \\
\hline Barras de cereais & Barras de cereais & 20,02 & 40,5 & 20,48 & 102 \\
\hline \multirow{4}{*}{ Alimentação preparada } & Bases de pizza & 2,96 & 12,74 & 9,78 & 330 \\
\hline & Lasanha & 4,84 & 16,75 & 11,91 & 246 \\
\hline & Panados de peixe & 11,15 & 13,37 & 2,22 & 20 \\
\hline & Pizza cong elada & 7,61 & 14,26 & 6,65 & 87 \\
\hline
\end{tabular}

\section{Gráfico 2}

Preços médios por tipo de marca

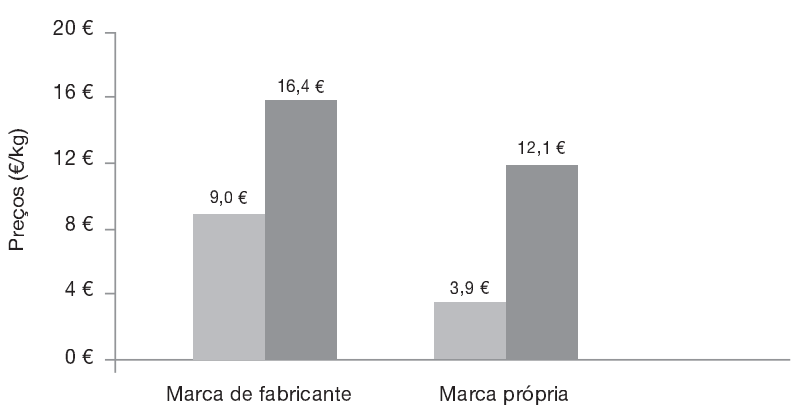

Com glúten Sem glúten

preparada e cereais de pequeno-almoço. No pão, massas e farinha verificou-se uma diminuição do preço dos PAESG.

\section{DISCUSSÃO DOS RESULTADOS}

Este trabalho pretende ser uma fonte de informação acerca dos preços dos PAESG, da sua discrepância em relação aos equiparáveis com glúten e da despesa destes produtos enquadrada no rendimento familiar. Esta informação poderá ser utilizada pelos portadores de doença celíaca e seus familiares, setor da restauração/ hotelaria e indústria alimentar, através da perceção dos produtos onde está identificada maior diferença de preços, como indicativo do nível de oferta, otimizando a gama de PAESG.

Os preços tratados no estudo resultam de dados recolhidos por consulta online, o que permite uma uniformização dos preços médios relativamente às variações de preços em Portugal Continental, não refletindo as variações de preço associadas a uma maior ou menor disponibilidade de PAESG, nem de promoções pontuais. Das lojas estudadas duas são de venda online com preços padronizados

\section{Gráfico 3}

Preços médios por tipo de loja

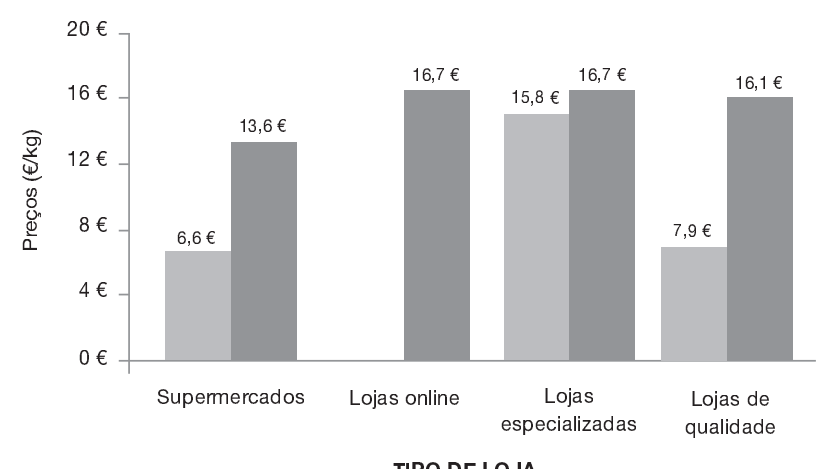

TIPO DE LOJA para todo o país. Um estudo de caracterização de uma amostra de indivíduos com doença celíaca (9), indica que 14\% dos inquiridos adquire PAESG através de sites portugueses.

Os PAESG foram analisados em 4 tipos de loja distintos, correspondentes às principais tipologias de pontos de venda onde se encontram disponíveis. O levantamento de dados do preço dos produtos com glúten foi feito nos supermercados, por serem o único tipo de loja em que era possível a recolha de igual número de preços, por tipo de produto, face aos produtos encontrados sem glúten, sem limitações na oferta. Foi considerada a escolha dos alimentos com glúten mais e menos dispendiosos através da recolha dos preços máximos e mínimos. Esta abordagem possibilitou um resultado de referência de preço, por tipo de produto, dos produtos com glúten. No entanto, a análise dos dados apresentada não permite a comparação da diferença entre os PAESG e os com glúten, consideradas as escolhas mais e/ou menos dispendiosas por tipo de produto.

Conforme se demonstra no presente estudo em que o preço dos PAESG foi mais elevado em todas as categorias de produtos analisadas, 
Análise do custo do cabaz alimentar essencial com e sem glúten no rendimento familiar

\begin{tabular}{|c|c|c|c|c|c|c|c|c|c|}
\hline \multirow[b]{2}{*}{$\begin{array}{l}\text { PRODUTOS DO } \\
\text { CABAZ }\end{array}$} & \multirow[b]{2}{*}{$\begin{array}{l}\text { QUANTIDADE DE } \\
\text { ALIMENTOS POR SEMANA }\end{array}$} & \multirow{2}{*}{$\begin{array}{c}\text { PREÇOS } \\
\text { JANEIRO } 2011 \\
\text { CUSTO MÉDIO } \\
\text { CABAZ COM } \\
\text { GLÚTEN (€) }\end{array}$} & \multirow[t]{2}{*}{ IPC 2011} & IPC 2012 & $\begin{array}{l}\text { IPC 2013 } \\
\text { (ATÉ 09.2013) }\end{array}$ & \multicolumn{4}{|c|}{ PREÇOS ATUALIZADOS } \\
\hline & & & & \multicolumn{2}{|c|}{$\begin{array}{l}\text { CLASSE } 1 \text { - } \\
\text { PRODUTOS ALIMENTARES }\end{array}$} & $\begin{array}{l}\text { CUSTO MÉDIO } \\
\text { CABAZ COM } \\
\text { GLUUTEN (€) }\end{array}$ & $\begin{array}{l}\text { ACRÉSCIMO } \\
\text { DE CUSTO } \\
\text { DOS PAESG }\end{array}$ & $\begin{array}{l}\text { CUSTO MÉDIO } \\
\text { CABAZ SEM } \\
\text { GLUTEN (€) }\end{array}$ & DIFERENÇA (€) \\
\hline Pão & 42 pães & 4,20 & 2,1 & 3,2 & 2,6 & 4,53 & $311 \%$ & 18,63 & 14,09 \\
\hline Cereais & 2 pacotes de $375 \mathrm{~g}$ & 3,36 & 2,1 & 3,2 & 2,6 & 3,63 & $145 \%$ & 8,88 & 5,26 \\
\hline Bolachas & 2,5 pacotes de $200 \mathrm{~g}$ & 1,50 & 2,1 & 3,2 & 2,6 & 1,62 & $175 \%$ & 4,45 & 2,83 \\
\hline Arroz & $1 \mathrm{~kg}$ & 0,85 & 2,1 & 3,2 & 2,6 & 0,92 & & 0,92 & \\
\hline Batata & $5 \mathrm{~kg}$ & 2,70 & 2,1 & 3,2 & 2,6 & 2,91 & & 2,91 & \\
\hline Massa & $1 \mathrm{~kg}$ & 1,07 & 2,1 & 3,2 & 2,6 & 1,15 & $300 \%$ & 4,62 & 3,46 \\
\hline Hortícolas & $16 \mathrm{~kg}$ & 25,28 & 2,1 & 3,2 & 2,6 & 27,28 & & 27,28 & \\
\hline Fruta & $14,5 \mathrm{~kg}$ & 19,43 & 2,1 & 3,2 & 2,6 & 20,96 & & 20,96 & \\
\hline Leite & $7,5 \mathrm{~L}$ & 5,40 & 2,1 & 3,2 & 2,6 & 5,83 & & 5,83 & \\
\hline logurte & $\begin{array}{l}4 \text { iogurtes líquidos ou } 6 \\
\text { iogurtes sólidos }\end{array}$ & 1,78 & 2,1 & 3,2 & 2,6 & 1,92 & & 1,92 & \\
\hline Queijo & $400 \mathrm{~g}$ & 3,32 & 2,1 & 3,2 & 2,6 & 3,58 & & 3,58 & \\
\hline Carne & $1 \mathrm{~kg}$ & 6,61 & 2,1 & 3,2 & 2,6 & 7,13 & & 7,13 & \\
\hline Peixe & $1 \mathrm{~kg}$ & 8,25 & 2,1 & 3,2 & 2,6 & 8,90 & & 8,90 & \\
\hline Ovos & 1 caixa de meia dúzia & 1,07 & 2,1 & 3,2 & 2,6 & 1,15 & & 1,15 & \\
\hline Leguminosas secas & $500 \mathrm{~g}$ & 0,71 & 2,1 & 3,2 & 2,6 & 0,77 & & 0,77 & \\
\hline Leguminosas frescas & $1,5 \mathrm{~kg}$ & 3,99 & 2,1 & 3,2 & 2,6 & 4,31 & & 4,31 & \\
\hline Manteiga/margarina & $1 / 3$ de caixa de manteiga & 0,15 & 2,1 & 3,2 & 2,6 & 0,16 & & 0,16 & \\
\hline Azeite/ óleo & $500 \mathrm{ml}$ & 1,13 & 2,1 & 3,2 & 2,6 & 1,22 & & 1,22 & \\
\hline Água & $37,1 \mathrm{~L}$ & 0,04 & 2,1 & 3,2 & 2,6 & 0,04 & & 0,04 & \\
\hline \multicolumn{2}{|c|}{ Total de familia - semanal } & 90,84 & & & & 98,0 & & 123,7 & 25,7 \\
\hline \multicolumn{2}{|c|}{ Média por pessoa - semanal } & 30,28 & & & & 32,7 & & 41,2 & 8,6 \\
\hline \multicolumn{2}{|c|}{ Média da familia - mensal (30 dias) } & 389,3 & & & & 420 & & 530 & 110 \\
\hline \multicolumn{2}{|c|}{ Média por pessoa - mensal (30 dias) } & 129,8 & & & & 140 & & 176,7 & 36,7 \\
\hline \multicolumn{5}{|c|}{ Contributo na Retribuição Mínima Nacional de dois adultos } & $970 €$ & $43 \%$ & & $55 \%$ & \\
\hline \multicolumn{5}{|c|}{ Contributo no Rendimento Médio Mensal de dois adultos } & $2546 €$ & $17 \%$ & & $21 \%$ & \\
\hline
\end{tabular}

IPC: Índice de Preços no Consumidor

PAESG: Produtos Alimentares Específicos Sem Glúten

\section{Tabela 3}

Comparação dos resultados com um estudo de mercado realizado em 2006

\begin{tabular}{|c|c|c|c|c|c|c|c|c|c|c|c|}
\hline \multirow{2}{*}{ CATEGORIAS } & \multicolumn{4}{|c|}{ ESTUDO 2013} & \multicolumn{4}{|c|}{ ESTUDO 2006} & \multirow{2}{*}{$\begin{array}{c}\text { COMPARAÇÃO } \\
\text { DA } \\
\text { DIFERENÇA } \\
(\%)\end{array}$} & \multicolumn{2}{|c|}{$\begin{array}{l}\text { \% DE VARIAÇÃO } \\
\text { DO PREÇO }\end{array}$} \\
\hline & $\begin{array}{c}\text { MÉDIA } \\
\text { GLUUTEN (€) }\end{array}$ & $\begin{array}{c}\text { MÉDIA } \\
\text { PAESG (€) }\end{array}$ & $\begin{array}{l}\text { DIFERENÇA } \\
(€)\end{array}$ & $\begin{array}{l}\text { DIFERENÇA } \\
(\%)\end{array}$ & $\begin{array}{c}\text { MÉDIA } \\
\text { GLÚTEN (€) }\end{array}$ & $\begin{array}{c}\text { MÉDIA } \\
\text { PAESG (€) }\end{array}$ & $\begin{array}{l}\text { DIFERENÇA } \\
(\epsilon)\end{array}$ & $\begin{array}{l}\text { DIFERENÇA } \\
(\%)\end{array}$ & & $\begin{array}{c}\text { MÉDIA } \\
\text { GLÚTEN (\%) }\end{array}$ & $\begin{array}{c}\text { MÉDIA } \\
\text { PAESG (\%) }\end{array}$ \\
\hline $\begin{array}{l}\text { Alimentação } \\
\text { Preparada }\end{array}$ & 7 & 14,5 & 7,5 & 107 & 7,6 & 13,5 & 5,9 & 77 & 30 & $-8,4$ & 7,4 \\
\hline $\begin{array}{l}\text { Barras de } \\
\text { cereais }\end{array}$ & 20 & 40,5 & 20,5 & 102 & 14 & 31 & 16,9 & 121 & -19 & 42,8 & 30,8 \\
\hline $\begin{array}{l}\text { Bolachas } \\
\text { / Bolos }\end{array}$ & 8,7 & 21,1 & 12,4 & 141 & 3,2 & 9,3 & 6,1 & 189 & -48 & 171,4 & 127 \\
\hline $\begin{array}{l}\text { Cereais de } \\
\text { pequeno- } \\
\text { almoço }\end{array}$ & 6,2 & 13,2 & 7 & 112 & 6,5 & 12 & 5,5 & 83 & 29 & $-4,7$ & 10,2 \\
\hline Farinha & 4 & 6,6 & 2,6 & 65 & 1,4 & 9,2 & 7,8 & 543 & -478 & 175,7 & $-29,2$ \\
\hline Massas & 2,1 & 8,5 & 6,4 & 300 & 2,2 & 9,2 & 7,1 & 328 & -28 & $-1,9$ & $-8,1$ \\
\hline Pão & 5,2 & 15,6 & 10,4 & 201 & 3,8 & 15,7 & 11,8 & 308 & -107 & 34,6 & $-0,7$ \\
\hline
\end{tabular}

PAESG: Produtos Alimentares Específicos Sem Glúten

a DIG tende a ser mais dispendiosa do que a alimentação convencional, resultado em concordância com estudos realizados noutros países. No Brasil, os PAESG são em média 138\% mais elevados (16). Estudos realizados nos Estados Unidos da América (15) e Reino Unido (25) aferiram que, em geral, o custo dos PAESG tende a ser 2 a 3 vezes mais elevado face ao preço dos produtos regulares com glúten. No Canadá (7), foram comparados preços de 56 PAESG com alimentos regulares das mesmas categorias e constatou-se que os
PAESG eram, em média, 242\% mais caros que os alimentos convencionais equivalentes.

As maiores diferenças de preço em relação aos alimentos com glúten foram encontradas nas categorias das massas, pão e bolachas, grupos de alimentos considerados essenciais na alimentação diária considerando uma dieta completa, equilibrada e variada (19). As menores diferenças percentuais verificaram-se nas categorias da farinha, barras de cereais e alimentação preparada. 
Na Tabela 3, com a comparação dos resultados da presente recolha de dados com um estudo realizado em 2006 (24), verificou-se que a diferença entre preços de PAESG e com glúten diminuiu na maioria das categorias, podendo este decréscimo ser justificado pela maior variedade de marcas e tipos de produtos sem glúten disponíveis no mercado. No pão, massas e farinha verificou-se uma diminuição do preço dos PAESG, eventualmente, devido ao surgimento de marcas próprias nestas categorias de produtos.

Nos tipos de produtos analisados que integram as categorias definidas, a massa esparguete foi o alimento onde se registaram maiores diferenças de preço entre os PAESG e os com glúten, foi possível identificar que não se incluiu nenhum dado relativo a este tipo de produto sem glúten de marca própria, tal como nos outros tipos de massas analisados (espirais e macarrão), onde se encontram as mais elevadas diferenças de preços. Esta constatação dá indicação à indústria alimentar da oportunidade do desenvolvimento de novos PEASG integrados na categoria das massas alimentícias, sob diversas variedades. No estudo realizado em 2006 , as farinhas específicas sem glúten apresentavam uma diferença de $891 \%$ relativamente às com glúten, atualmente, a farinha para bolos e para panificação têm uma diferença de 42 e 142\%, respetivamente. O aumento da comercialização de uma vasta gama de preparados de farinha para bolos e panificação com glúten (adequados às máquinas de pão) a preços mais elevados do que a tradicional farinha de trigo, pode representar uma causa justificativa para esta menor diferença, tal como, o aumento do número de marcas de fabricante e marcas próprias de farinhas específicas sem glúten.

Verificou-se que os PAESG têm um menor aumento de preço entre as marcas de fabricante e as marcas próprias (35\%) do que os produtos com glúten (126\%).

O custo dos PAESG por tipo de loja demonstrou ser muito semeIhante nas lojas online, lojas especializadas e lojas de qualidade, sendo os supermercados a apresentar os menores preços. De forma semelhante, nos Estados Unidos da América, as grandes superfícies são as lojas menos dispendiosas para adquirir os PAESG, seguindo-se as lojas de qualidade, lojas especializadas, e por último, as lojas online são as mais caras (15). Os supermercados/hipermercados constituem o principal local de aquisição de PAESG, segundo um estudo nacional, cerca de $34 \%$ dos participantes integrados na amostra afirmou comprar, com uma frequência semanal, este tipo de produtos nas grandes superfícies, sendo as lojas especializadas o segundo local preferencial de aquisição (9).

O cabaz essencial para um indivíduo a seguir a DIG tem um acréscimo de 8,6 € semanal em relação ao equivalente com glúten, para um agregado familiar de 3 pessoas a seguir a DIG a despesa acresce em $110 €$ por mês. Valores que vão de encontro à estimativa feita pelos portadores de doença celíaca portugueses que assinalam aumentos na despesa semanal, que variam de 7 a $200 €$ (9).

No Reino Unido, $46 \%$ das pessoas com doença celíaca acredita que a sua alimentação era mais dispendiosa do que a alimentação dos indivíduos sem restrições alimentares, estimando uma diferença média de $15 €$ por semana (26). Em Espanha, uma família com um individuo com doença celíaca, com uma dieta de 2000 a 2300 quilocalorias, pode aumentar o seu gasto no cabaz de compras em 33,67 € por semana, o que significa um acréscimo de 134,7 € mês (17).

Analisando a despesa associada ao cumprimento da DIG no orçamento familiar de um agregado familiar constituído por dois adultos e um adolescente: contando com a retribuição mínima nacional de dois adultos, as despesas com a alimentação sem glúten para toda a família representam $55 \%$ do rendimento, um acréscimo de 12\% em relação ao cabaz com glúten; considerando o rendimento médio líquido a despesa pesa $21 \%$.

Dados reportam a incidência de uma componente hereditária associada à DC $(27,28)$. Verificou-se, que $11,4 \%$ das pessoas com doença celíaca, inquiridas e alvo de estudo, tinham conhecimento de familiares com a doença (9). A DIG pode ser adotada por toda a família, considerando o apoio psicológico que representa (principalmente no caso da crianças e adolescentes). A probabilidade de existir mais do que um indivíduo com doença celíaca por agregado familiar, e de forma a minimizar as contaminações cruzadas na preparação e confeção das refeições, acresce o peso das despesas associadas à alimentação no rendimento da família.

É comum os indivíduos com doença celíaca mencionarem outras intolerâncias alimentares, sendo a intolerância à lactose a mais habitual (29). Cerca de $23 \%$ dos participantes, num estudo, referiram apresentar outras alergias/ intolerâncias alimentares e destes 15\% aludiram ter intolerância à lactose (9), percentagem idêntica à encontrada num estudo canadiano, em que se verificou que 18\% dos inquiridos apresentavam intolerância à lactose (30). Para além do custo acrescido da DIG, nos casos de intolerância à lactose, há um acréscimo no peso das despesas com alimentação, associado ao custo mais elevado destes alimentos em comparação com os equivalentes com lactose (31). A DIG tende a incluir mais fruta, hortícolas, carne e pescado, atentando que estes alimentos são naturalmente isentos de glúten e se encontram mais disponíveis que os PAESG (15). Indo ao encontro dos resultados encontrados aquando da caracterização de uma amostra de indivíduos com doença celíaca, em que mais de metade dos participantes considerava que a sua alimentação atual era mais saudável comparativamente à que realizavam antes de serem diagnosticados (9). Vários estudos associam o consumo de fruta, hortícolas e alimentos não processados a aumentos no custo da dieta (32-34). No cabaz alimentar essencial (tabela 2) podemos perceber que são as categorias da fruta, hortícolas, carne e peixe que têm os preços mais elevados, contribuindo adicionalmente para aumentos nas despesas com a alimentação dos indivíduos com doença celíaca.

Atualmente, os portadores de DC podem inserir em sede de IRS, nas despesas de saúde taxadas a IVA reduzido, as despesas gastas com os alimentos específicos sem glúten (35). As pessoas com doença celíaca até aos 24 anos, ou até iniciarem atividade laboral podem requerer o abono complementar de deficiência junto da segurança social (36).

Um maior conhecimento por parte da sociedade portuguesa e a certeza de que a alimentação sem glúten é o único tratamento da $\mathrm{DC}$, pode constituir um estímulo à indústria alimentar para uma maior produção e oferta de alimentos, potencialmente a custos mais reduzidos, mas também a uma maior sensibilidade das autoridades para gerar medidas de apoio social, sobretudo nos casos de famílias com baixos rendimentos, considerando a fatia atribuída às despesas com a alimentação sem glúten.

\section{CONCLUSÕES}

O presente estudo demonstra que, em todas as categorias, os PAESG estudados são mais dispendiosos que os produtos alimentares equiparáveis com glúten. Os supermercados são a tipologia de lojas com os preços dos PAESG mais baixos, associados à comercialização das marcas próprias. O custo do cabaz alimentar essencial sem glúten é superior em relação ao equivalente com glúten, representando mais de metade do orçamento das famílias com 2 adultos, que auferem o ordenado mínimo nacional. Em comparação 
com um estudo realizado anteriormente a diferença entre preços de PAESG e com glúten diminuiu na maioria das categorias.

Considerando a atual situação socioeconómica, os resultados do preço da alimentação sem glúten podem refletir-se no cumprimento rigoroso da DIG, com consequências clínicas e nutricionais, associadas ao aumento do risco de complicações.

\section{REFERÊNCIAS BIBLIOGRÁFICAS}

1. Peter HR, Freen MD, Christophe C. Celiac Disease. N Eng J Med 2007. 357: $1731-43$.

2. Antunes H, Abreu I, Nogueiras A, Sá C, Gonçalves C, Cleto P, et al. Primeira determinação de prevalência de doença celíaca numa população portuguesa. Ata Med Port 2006; 19: 115-120

3. Hill ID, Dirks MH, Liptak GS, Colletti RB, Fasano A, Guandalini S, et al . Guideline for the Diagnosis and Treatment of Celiac Disease in Children: Recommendations of the North American Society for Pediatric Gastroenterology, Hepatology and Nutrition. J Pediatr Gastroenterol Nutr 2005; 40(1): 1-19.

4. Bai JC, Fried M, Corazza GR, Schuppan D, Farthing M, Catassi C, et al. World Gastroenterology Organisation Global Guidelines on Celiac Disease. J Clin Gastroenterol 2013 Fev; 47(2): 121-126.

5. Schuppan D, Dennis MD, Kelly CP. Celiac Disease: Epidemiology, Pathogenesis, Diagnosis, and Nutritional Management. Nutr Clin Care 2005; 8(2): 54-69.

6. REGULAMENTO (CE) N.o 41/2009 DA COMISSÃO de 20 de janeiro de 2009 relativo à composição e rotulagem dos géneros alimentícios adequados a pessoas com intolerância ao glúten.

7. Sevens L, Rashid M. Gluten-free and regular foods: a cost comparison. Can J Diet Pract Res. 2008; 69(3):147-50.

8. Batista R, Carmo MF, Jorge R, Tomás T, Cardoso M, Moreira AC, et al. Conhecimentos sobre doença celíaca e cumprimento da dieta isenta de glúten. APNEP. 2008 dez; II(2):97-101.

9. Martins AS. Ser Celíaco em Portugal: Caracterização de uma amostra de celíacos [tese de mestrado]. Porto: Universidade Católica Portuguesa; 2012.

10. Asseiceira I, Carriço J, Azevedo S, Lopes Al. Grau de adesão e fatores interferentes no cumprimento da dieta isenta em glúten em crianças e adolescentes com doença celíaca. APNEP. 2012 julho; VI(1):75.

11. Tack GJ, Verbeek WHM, Schreurs MWJ, Mulder CJJ. The spectrum of celiac disease: epidemiology, clinical aspects and treatment. Nat Rev Gastroenterol Hepatol. 2010; 7:204-213.

12. Catassi C, Bearzi I, Holmes GKT. Association of Celiac Disease and Intestinal Lymphomas and Other Cancers. Gastroenterology. 2005; 128:S79-S86.

13. Goddard CJR, Gillet HR. Complications of celiac disease: are all patients at risk? PMJ. 2006; 82:705-712.

14. Case S. The gluten-free diet: How to provide effective education and resources. Gastroenterology. 2005 abril; 128(4):S128-S134.

15. Lee AR, Ng DL, Zivin J, Green PHR. Economic burden of a gluten-free diet. J Hum Nutr Diet. 2007; 20:423-30.

16. Paim V, Schuck C. O custo da alimentação sem glúten no Brasil [internet]. 2010 jan 8 [consultado em: 11 de novembro de 2013]. Disponível em: http://www. vidasemglutenealergias.com/o-custo-da-alimentacao-sem-gluten-no-brasil/609/.

17. Face. Informe de precios sobre productos sen gluten 2013 [internet]. 2013 [consultado em: 11 de novembro de 2013].

Disponível em: http://www.celiacos.org/images/stories/pdf/informedeprecios2013.pdf 18. Graça P. Portugal - Alimentação Saudável em números - 2013. Lisboa: Direção Geral da Saúde; 2013.

19. Cordeiro T, Dias D, Real H, Martins A, Bento A. Cabaz alimentar essencial. Nutrícias. 2011 maio; 11:2-6;

20. Instituto Nacional de Estatística. Índice de preços no consumidor - setembro de 2013. Destaque. 2013 out 10.

21. Taxa de variação média dos últimos doze meses do IPC diminuiu para 0,6\% outubro de 2013 [internet] 2013 nov 12 [consultado em 13 de novembro de 2013].
Disponível em: http://www.ine.pt/xportal/xmain?xpid=INE\&xpgid=ine_destaques\&DESTAQUESdest_boui $=151509250 \& D E S T A Q U E S m o d o=2$

22. INE. Inquérito às Despesas das Famílias 2010/2011. Lisboa: Instituto Nacional de Estatística, I.P; 2008.

23. Decreto-Lei n. ${ }^{\circ}$ 143/2010 de 31 de dezembro, Estabelece a Retríbuição Mínima Mensal Garantida. $1^{\circ}$ Série; 6121.

24. Produtos com e sem glúten: os preços comparados. Sem Glúten. 2006 agosto; $16:$ : -10 .

25. Singh J, Whelan K. Limited availability and higher cost of gluten-free foods. J Hum Nutri Diet. 2011; 24:479-86.

26. Whiaker JKH, West J, Holmes GKT, Logan RFA. Patiens perceptions of the burden of celiac disease and its treatment in the UK. Aliment Pharmacol Ther. 2009. 29: 1131-1136.

27. Van Heel DA. Genetics in coelic disease. Best Pract Res CI Ga. 2005; 19(3):323-339. 28. Heap GA, van Heel DA. Genetics and phatogenesis of celiac disease. Seminars in Immunology. 2009; 21: 346-354.

29. Murray JA. The widening spectrum of celiac disease. Am J Clin Nutr. 1999; 69:354-365.

30. Cranney A, Zarkadas M, Graham ID, Butzner JD, Rashid M, Warren R, et al. The Canadian Celiac Health Survey. Dig Dis Sci. 2007; 52:1087-1095.

31. Dairy and lactose intolerance [internet]. [consultado em 2013 novembro 27]. Disponível em: http://www.milk.co.uk/page.aspx?intPagelD=139.

32. Cade J. Upmeier H, Calvert C, Greenwood D. Costs of a healthy diet: analysis from the UK Women's Cohort Study. Public Health Nutr. 1999; 2:505-512.

33. Raynor HA, Kilanowski CK, Esterlis I, Epstein LH. A cost-analysis of adopting a healthful diet in a family-based obesity treatment program. 2002; 102:645-656.

34. Drewnowski A, Darmon N, Briend A. Replacing fats and sweets with vegetables and fruits - a question of cost. Am J Public Health. 2004; 94:1555-1559.

35. Circular N. ${ }^{\circ} 17$ /2009. Despesas de saúde. Produtos sem glúten. Direção-Geral dos Impostos, 17 de junho de 2009.

36. Bonificação do abono de família para crianças e jovens com deficiência [internet]. [atualizado em 2012 fevereiro 20; consultado em 2013 novembro 27].

Disponível em: http://www4.seg-social.pt/bonificacao-do-abono-de-familia-para-criancas-e-jovens-com-deficiencia. 